\title{
OBITUARIO
}

\section{ROMEO CARNEVALI}

(1919-2008)

El 15 de enero de 2008 falleció, en la ciudad de Corrientes, el Ing. Agr. Romeo Carnevali. Italiano de nacimiento, vio la luz en Bologna el 8 de agosto de 1919, vivió en la Argentina desde los cuatro años de edad, cuando su familia se estableció en Buenos Aires. Allí cursó todos sus estudios y en 1944 obtuvo el título de Ingeniero Agrónomo en la Facultad de Agronomía de la Universidad de Buenos Aires. En 1946 llegó a la ciudad de Corrientes donde se radicó definitivamente y formó su familia integrada por su esposa Olga y sus hijos Nora y Ernesto.

Inició su carrera docente como Profesor Titular de la cátedra de Botánica de la Facultad de Agricultura, Ganadería e Industrias y Afines de la Universidad Nacional del Litoral, más tarde Facultad de Agronomía y Veterinaria

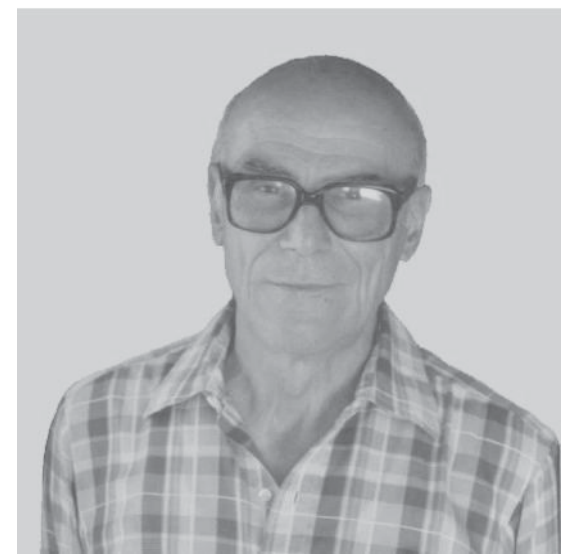
de la Universidad Nacional del Nordeste. En esta Universidad se desempeñó posteriormente como Profesor de la cátedra de Botánica de la Escuela Regional de Agricultura, Ganadería e Industria y Afines (ERAGIA) y como Profesor Titular Interino «ad honorem» de la cátedra Botánica I, en la Facultad de Ciencias Exactas y Naturales y Agrimensura.

Fue Director General del Departamento de Economía Agropecuaria y Director de la Administración de Bosques de la provincia de Corrientes. Técnico Investigador en el Instituto Nacional de Tecnología Agropecuaria (INTA), desarrolló sus actividades en la Estación Experimental Agropecuaria de Corrientes, hasta su jubilación.

Miembro de la Sociedad Argentina de Botánica y de la Asociación Argentina de Ecología, participó de numerosas reuniones científicas nacionales e internacionales.

El Instituto de Botánica del Nordeste lo contó entre sus colaboradores permanentes, y el Herbario CTES se enriqueció con la donación de los ejemplares testigos de sus viajes de recolección.

Contribuyó, mediante publicaciones de su autoría y como coautor, al conocimiento de los suelos y la vegetación de la provincia de Corrientes. Uno de sus trabajos, la Fitogeografía de la Provincia de Corrientes, publicado en 1994 con el auspicio del INTA y el Gobierno de la provincia, merece un párrafo aparte. Volcó en esta publicación los resultados de más de veinte años durante los cuales caminó toda la región. Observó, realizó censos, recolectó e identificó ejemplares de herbario, definió tipos fisonómicos, delimitó y describió unidades de vegetación y ambiente y sus elementos florísticos constitutivos. Su trabajo meticuloso y crítico se refleja en la riqueza de la información que brinda la obra, en la clara delimitación de los territorios fitogeográficos y la caracterización de sus unidades de paisaje, en la detallada descripción de las comunidades vegetales, y en la carta fitogeográfica y la de unidades de paisaje que constituyen una acabada síntesis de la fitogeografía de la provincia.

La obra se ha constituido en referencia obligada para los estudios de vegetación, recursos naturales o prácticas agropecuarias que se encaran en toda la provincia de Corrientes.

El Proyecto Iberá, programa especial de investigación implementado en 1999 por la Universidad Nacional del Nordeste, lo contó entre sus investigadores. Ya con más de ochenta años participó, con los bríos y el entusiasmo de un joven, en los viajes de campaña al macrosistema realizados por los grupos de investigación. Los resultados de su trabajo, El Iberá y su entorno fitogeográfico, vieron la luz en el año 2003. 
Apasionado por la naturaleza y por su provincia de adopción, trabajó con entusiasmo casi hasta el final de sus días. Su última producción fue el capítulo Diversidad vegetal del Microsistema Iberá, del "Manual de Biodiversidad de Chaco, Corrientes y Formosa", actualmente en prensa.

Su conocimiento de los paisajes, el suelo y la vegetación de Corrientes era vasto, sólido, y no lo retaceaba a nadie. Quien compartía sus viajes al campo estaba seguro de que gozaría de jornadas de fructífero aprendizaje, además del placer de su compañía. Con una amplia cultura general, podía departir tanto acerca de temas propios de su especialidad como de distintas ramas del arte, de la historia o de geografía.

Puso también su saber y energía al servicio de la sociedad correntina. Participó activamente en la elaboración del proyecto y creación del Jardín Botánico «Nuestra Sra. del Huerto» de la ciudad de Corrientes. El salón de usos múltiples de dicho Jardín lleva hoy su nombre en reconocimiento a su permanente colaboración.

Tuve el privilegio de pertenecer al plantel docente de la cátedra en la que se desempeñó como Profesor Titular hasta su retiro de la docencia universitaria. Esta relación, los viajes de estudio que compartimos y las largas charlas mantenidas en el IBONE, me permitieron conocer su capacidad como profesional, y descubrir las virtudes personales que lo distinguían, generosidad, modestia, honestidad, rectitud.

Dotado de virtudes que caracterizan a unos pocos elegidos, se brindó por entero a sus alumnos, sus colegas, sus amigos, a la sociedad toda que ha perdido este año a un referente del saber.

Sara G. Tressens 


\section{OBITUARIO}

\section{FEDERICO BERNARDO VERVOORST}

(1923-2008)

Federico B. Vervoorst falleció el viernes 20 de junio de 2008 en la ciudad de San Miguel de Tucumán, a los 85 años como consecuencia de un paro cardíaco. Nació el 29 de abril de 1923 en la ciudad de Santa Fe.

Estudió en la Universidad de Buenos Aires donde obtuvo el título de Licenciado en Ciencias Naturales en 1948. Se inscribió en la carrera de Geología, pero su profesor Don Alberto Castellanos lo incitó a cambiar su orientación por la botánica. Es así que en mayo de 1954 presentó a la Facultad de Ciencias Exactas y Naturales de la Universidad de Buenos Aires su trabajo de tesis «Observaciones ecológicas y fitosociológicas en el bosque de algarrobo del Pilciao (Catamarca)», apadrinado por el Dr. Alberto Castellanos, para optar al grado de Doctor en Ciencias Naturales.

Su actividad docente se inició entre 1947 y 1949 en la Cátedra de Botánica de la FCEyNUBA, para continuar hasta 1954 en la Universidad Nacional de Tucumán y en el Instituto M. Lillo. Al no renovársele el contrato por razones políticas se trasladó a Chile donde actuó en el Instituto de Botánica de la Universidad de Concepción desde julio 1954 hasta 1955. A su vuelta al país se reincorporó al Instituto M. Lillo en febrero de 1967, donde permaneció hasta junio de 1992, fecha de su jubilación. Entre agosto de 1956 y enero de 1967 se desempeñó en el Instituto de Botánica Agrícola del Ministerio de Agricultura de la Nación y del INTA después. En este período realizó su magnífico estudio sobre la vegetación de la depresión del Salado en la provincia de Buenos Aires.

Cuando estudiante tuvo espléndidos maestros, a Alberto Castellanos en Botánica, Paul Groeber en Geografía Física y Climatología, Horacio A. Harrington en Geología, Martín Doello Jurado en Paleontología, Franco Pastore en Mineralogía y Petrografía, etc. Entre octubre 1954 y diciembre 1955 estudió palinología con el Dr. Franz Firbas, en la Universidad de Göttingen, con una beca de la Alexander von Humboldt-Stiftung de Bonn, Alemania.

En el Instituto M. Lillo, durante 1949-1950, trabajó junto con el Dr. Kurt Hueck para especializarse en Fitogeografía y Fitosociología. Trabó relación con los profesores H. Sleumer, W. Czajka, G. Fochler-Hauke, J. Mackenzie Lamb, R. Singer y B. Sparre, que fueron de gran beneficio para ampliar sus conocimientos. Por su actividad científica fue designado Académico Correspondiente de la Academia Nacional de Ciencias, en Córdoba, en junio de 1981, presidente de la Sociedad Argentina de Botánica durante el período 1986-1988 y Miembro Vitalicio de la Sociedad Científica Argentina y de la Asociación Geológica Argentina.

Conocí a Federico en octubre de 1948, durante el II Congreso Sudamericano de Botánica que se celebró en Tucumán, donde fue Secretario de la sección Sistemática de Plantas Celulares (Fósiles). Desde entonces hemos mantenido una estrecha relación, tanto profesional como personal. Tuve el privilegio de gozar de su conocimiento sobre aspectos científicos como también sobre personas del pasado y del presente. Su honestidad y su probidad le hicieron ganar el respeto de quienes tuvimos el honor de tratarlo. No dejó descendencia directa, pero sus sobrinas Sewerin, interpretando su voluntad, traspasaron su rica biblioteca al Instituto de Botánica del Nordeste. 


\section{Publicaciones}

1950-1951. Zur Vegetation am Salar de Pipanaco in der Provinz Catamarca, Argentinien. Die Erde, Zeitschriff Gesellchaft f. Erdkunde Berlin, Heft 2 (Argentinien): 190-191.

1955. Observaciones sobre la vegetación entre Tinogasta y la cuenca. En: Resultados de un viaje a la cuenca de la Laguna Verde, Tinogasta, Catamarca. Actas XV Semana de Geografía, Sociedad Argentina de Estudios Geográficos: 61-67. Mendoza.

1956. Die naturraumliche Gliederung Nordwest-Argentiniensis. Petermann’s Geographische Mitteilungen Jahrg. 100, Heft 2: 89-109, Heft 3: 196-208. En colaboración con W. Czajka.

1966. Guía para la excursión de la Sociedad Argentina de Botánica por las Provincias de Tucumán y Catamarca. Fundación M. Lillo. 32 pp.

1967. Las comunidades vegetales de la depresión del Salado (provincia de Buenos Aires). Serie Fitogeográfica, Instituto de Botánica Agrícola, INTA, No 7: 227 pp. 22 figs. 44 lám. 1 mapa de vegatación.

1969. Tillandsia albertiniana. The Bromeliad Bulletin 19(6): 128-129.

1969. Palabras de apertura de la Exposición en Homenaje al II Centenario del natalicio de Alexander von Humboldt. Fundación M. Lillo. Misceláneas 30: 9-13.

1969. Phytogeographycal provinces in north-west Argentina. En: J. G. Hawkes \& J. P. Hjerting (eds.). The potatoes of Argentina, Brazil, Paraguay and Uruguay. Chapter 3: Distribution andd ecology of wild species. Phytogeographical aspects. Annals of Botany, Memoirs 3: pp. 35, 37. Map 2.

1972. Lorentz y Hieronymus, primeros botánicos de la Academia de Ciencias de Córdoba. Boletín de la Academia Nacional de Ciencias 49: 63-70.

1976. Aclaraciones sobre una localidad de Lorentz. Kurtziana 9: 144-145.

1976. Nuevas localidades de Stenodrepanium bergii Harms. Kurtziana 9: 145.

1977. Phytogeographic settings of the study areas. En: G. Orians \& O. T. Solbrig (eds.). Convergent evolution in warm deserts. US/IBP Synthesis Series 1, 3: 16-25. 4 figs. En colaboración con B. B. Simpson.

1979. La vegetación del noroeste argentino y su degradación. Fundación M. Lillo, Serie Conservación de la Naturaleza 1: 5 pp. 1 mapa.

1981. Excursión botánica a Hualinchay, Tacanas y Gonzalo Trancas, Provincia de Tucumán. XVII Jornadas Argentinas de Botánica. 23 pp. En colaboración con P. R. Legname y A. Grau.

1982. Mapa de las comunidades vegetales de la Provincia de Tucumán. En: R. Laurent \& E. M. Terán (eds.). Lista de anfibios y reptiles de la Provincia de Tucumán. Fundación M. Lillo. Misceláneas 71: 8-9.

1982. Introducción. Región Noroeste. Simposio sobre la Conservación de la Vegetación Natural de la República Argentina. XVII Jornadas Argentinas de Botánica. Fundación M. Lillo, Serie Conservación de la Naturaleza 2: 724.

1983. Esquema fitogeográfico. Geología de la Sierra de Ancasti. Münster Forsch. Geol. Paläont. 59: 23-29. 2 figs. En colaboración con R. I. Fernández.

Antonio Krapovickas 